\title{
Expect the Unexpected: A Unique Association of Bicuspid Aortic Valve, with Severe Aortic Stenosis and Dilation of Ascending Aorta, with Cervical Vagus Nerve Schwannoma
}

\author{
Shivanand Patil, Rangaraj Ramalingam, Kasamshetty Subramanyam, Deepak Pujar, \\ Cholenahally Nanjappa Manjunath \\ Department of Cardiology, Sri Jayadeva Institute of Cardiovascular Sciences \& Research, Bangalore, India \\ Email: drssspatil@rediffmail.com
}

Received 25 March 2015; accepted 17 April 2015; published 22 April 2015

Copyright (C) 2015 by authors and Scientific Research Publishing Inc.

This work is licensed under the Creative Commons Attribution International License (CC BY).

http://creativecommons.org/licenses/by/4.0/

(c) (i) 0pen Access

\begin{abstract}
Hoarseness of voice is a common symptom of many laryngeal and extralaryngeal conditions. It is very crucial to identify the culprit behind it, keeping in mind all the various differentials. We report a case of a 35-year-old woman presenting with complaint of hoarseness of voice. Upon cardiac evaluation, the patient was diagnosed with bicuspid aortic valve, with severe aortic stenosis and dilation of ascending aorta. We suspected that the plausible reason for hoarseness of voice was compression of recurrent laryngeal nerve due to dilation of aorta, i.e., Ortner's syndrome. But to our surprise, CT of aorta and neck revealed extensive elongated cervical vagus nerve schwannoma. Such type of association is unique and new to voluminous medical literature.
\end{abstract}

\section{Keywords}

Ortner's Syndrome, Bicuspid Aortic Valve, Vagus Nerve, Schwannoma, Hoarseness of Voice

\section{Introduction}

Travelling back into the history of medical literature reminds us of an Austrian Physician, Nobert Ortner, who coined the term Ortner's syndrome. He attributed a case of left vocal cord immobility to compression of recurrent laryngeal nerve by a dilated left atrium in a patient with mitral valve stenosis [1]. With the passage of time,

How to cite this paper: Patil, S., et al. (2015) Expect the Unexpected: A Unique Association of Bicuspid Aortic Valve, with Severe Aortic Stenosis and Dilation of Ascending Aorta, with Cervical Vagus Nerve Schwannoma. International Journal of Clinical Medicine, 6, 281-284. http://dx.doi.org/10.4236/ijcm.2015.64035 
Ortner's syndrome encompasses much broader criteria and involves any non-malignant, cardiac, intrathoracic process that results in embarrassment of either recurrent laryngeal nerve, usually by stretching, pulling or compression, and causes vocal fold paralysis. Thus, Ortner's syndrome, also known as cardiovocal syndrome, is a rare condition which may be secondary to many cardiopulmonary disorders. Since then, many authors have described their experiences of recurrent laryngeal nerve involvement in various cardiac disorders such as Eisenmenger complex, left ventricular failure, atrial septal defect, patent ductus arteriosus, primary pulmonary hypertension, recurrent pulmonary artery embolism, mitral regurgitation, atrial myxomas, left ventricular aneurysm, cor pulmonale and various type of aortic aneurysm [2].

Thus, we present a rare and unique association of bicuspid aortic valve, with severe aortic stenosis and dilation of ascending aorta, presenting with hoarseness of voice. However, here the cause of hoarseness of voice was not Ortner's syndrome, but compression of recurrent laryngeal nerve by vagal nerve sheath schwannoma.

\section{Case-Report}

A 35-year-old woman was referred to our institute for evaluation of cardiac murmur. Her only complaint was hoarseness of voice since three months. Initial ENT examination revealed left vocal cord palsy. Upon interrogation, she denied history of exertional syncope, dyspnoea, chest pain and palpitation. On auscultation, ejection systolic murmur of grade 4 was audible at the aortic area, which radiated to the carotids. Echocardiogram revealed bicuspid aortic valve (BAV) (Figure 1 and Figure 2) with severe aortic stenosis and dilation of ascending aorta (Figure 3). We suspected compression of recurrent laryngeal nerve by aorta leading to hoarseness of voice. Hence, we decided to perform CT of aorta and neck. To our surprise, it revealed $60 \times 22$ mm elongated vagal nerve sheath tumor in relation to jugular fossa and cranial internal jugular vein (IJV) (Figure 4). The tumor displaced cervical internal carotid artery (ICA) anteriorly and left IJV posterior. The extension of lesion was seen till cerebellopontine (CP) angle with effacement of cerebellum and erosion of bones. Surgical excision is the treatment of choice in such cases.

\section{Discussion}

Hoarseness of voice is the usual presenting symptom of many laryngeal and extralaryngeal conditions [3]. The most common laryngeal cause is Ortner's syndrome, also known as a cardio-vocal syndrome [1]. Thus, the presenting symptom, hoarseness of voice, and subsequent diagnosis of bicuspid aortic valve (BAV) with severe aortic stenosis and dilation of ascending aorta aroused inevitable suspicion that this might be a case of Ortner's syndrome.

BAV is one of the rare congenital anomaly, which occurs when aortic valve does not develop in the normal fashion. The reported prevalence of BAV in medical literature is about $0.9 \%-2 \%$ with a male preponderance [4]. It is mainly associated with secondary aortopathy and valvulopathy like aortic dilation and calcific aorticvalve disease (CAVD) [5]. Some patients experience varied catastrophic complications due to BAV, while in some patients it is just an innocent bystander.

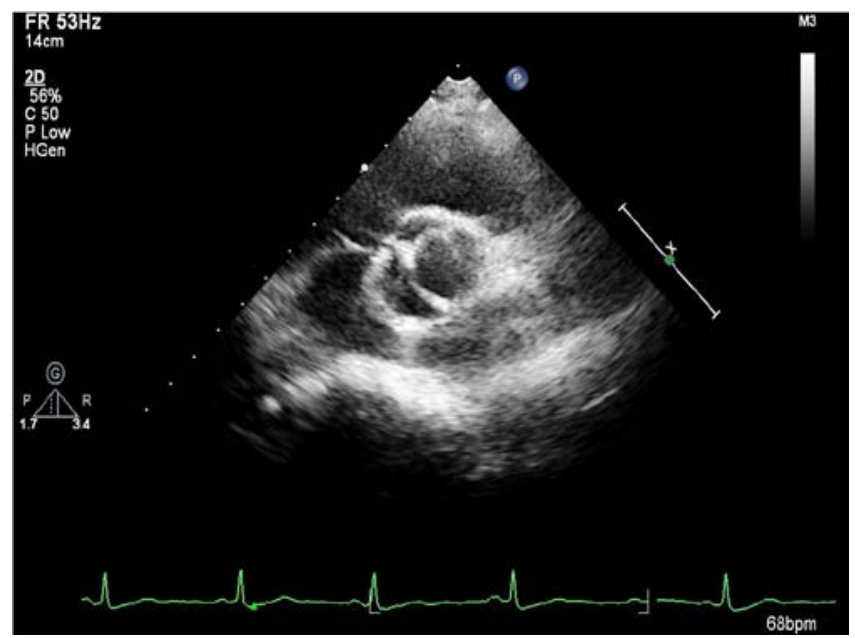

Figure 1. Echocardiogram revealing bicuspid aortic valve disease. 


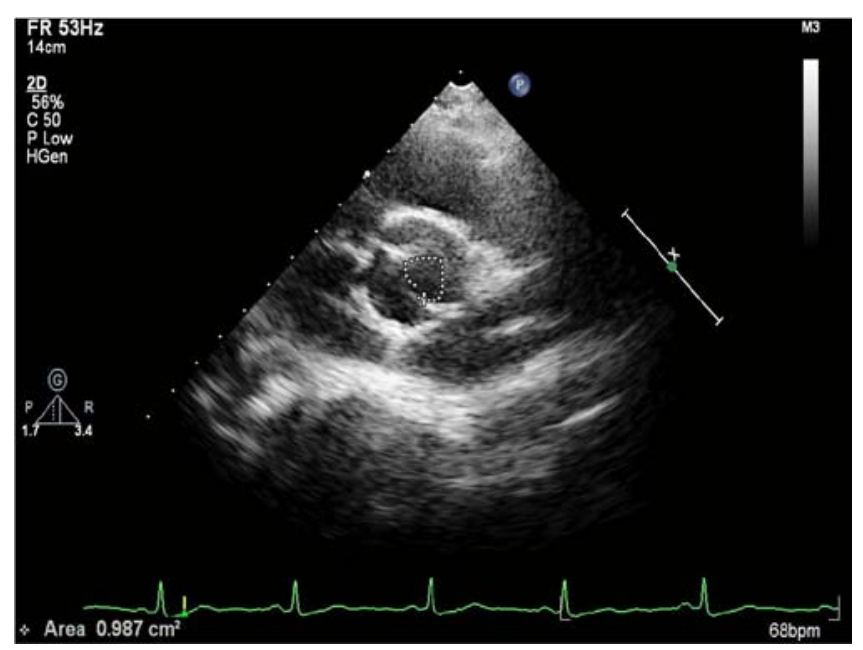

Figure 2. Echocardiogram showing valve area.

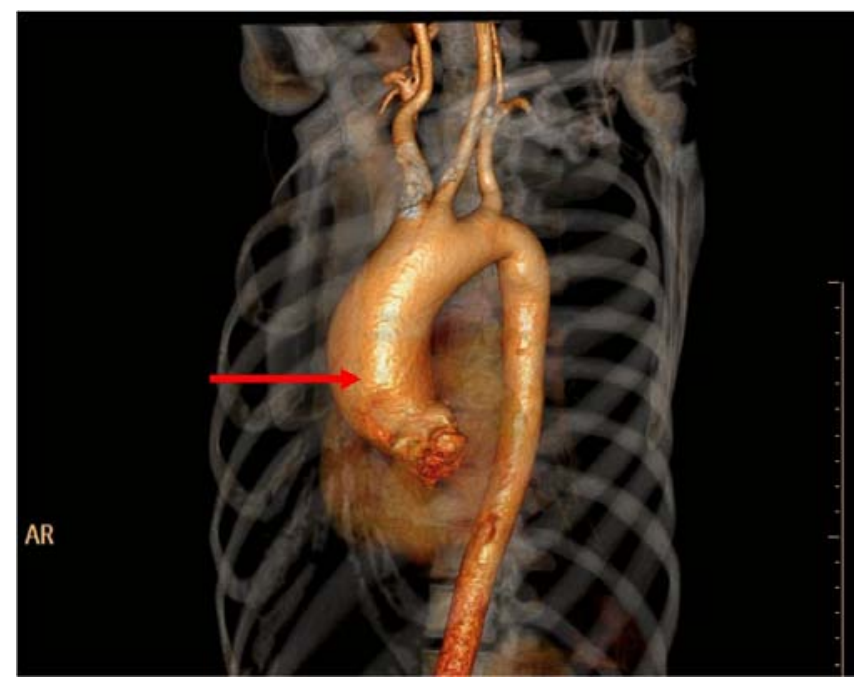

Figure 3. CT of aorta showing dilation of ascending aorta.

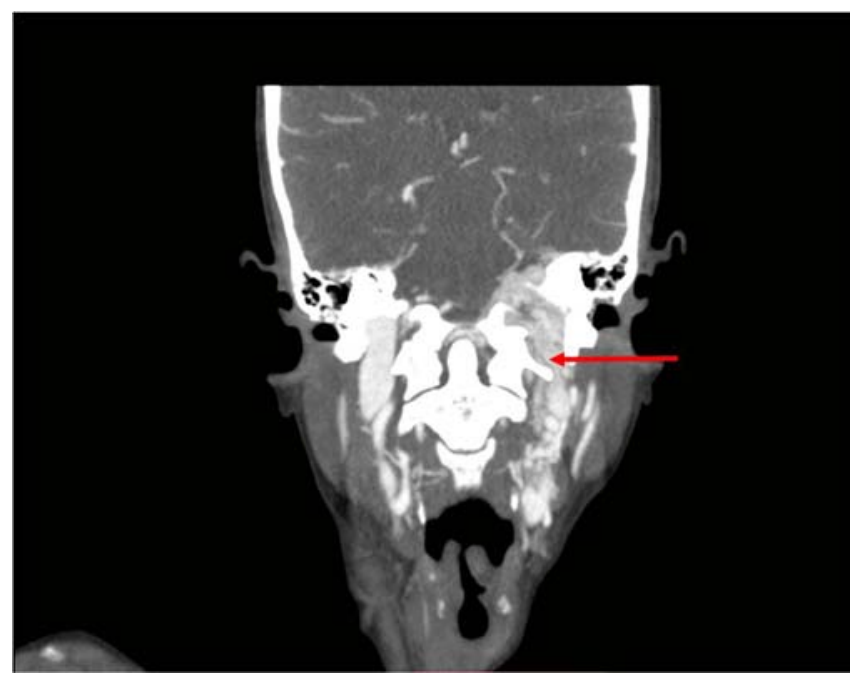

Figure 4. CT of neck showing vagal nerve schwannoma. 
The plausible reason for hoarseness of voice was compression of recurrent laryngeal nerve due to dilatation of aorta. Thus, CT of aorta and neck was done, which to our curiosity revealed extensive elongated vagal nerve schwannoma which was compressing the recurrent laryngeal nerve.

Schwannoma, also known as neurilemmomas, neuromas, or neurinomas are uncommon nerve sheath neoplasms that may arise from any peripheral, cranial or autonomic nerve of the body with the exception of olfactory and optic nerves [6]. Schwannoma arising from vagal nerve sheath is a rare benign tumor with prevalence of about 2\% - 5\% [7]. These tumors mostly occur between third and fifth decade of life and there is no sex predilection as reported in most of the studies [8]. The clinical picture usually consists of asymptomatic lateral and cervical isolated mass, insidiously expanding in volume, and consequently causing dysphagia or pharyngeal discomfort and hoarseness of voice due to compression of esophagus or pharynx and vagus nerve respectively.

Pre-operative diagnosis of schwannoma is not easy, particularly when there are no clinical signs or neurological deficits. Even, in our case, the patient's only complaint was hoarseness of voice without any specific symptoms, outlined in the literature, like dysphagia, dyspnea, cough, tongue weakness and bulging or swelling in the neck [9].

Such association of bicuspid aortic valve, with severe aortic stenosis and dilation of ascending aorta, with cervical vagus nerve schwannoma is very unique and it has not been described in the medical literature till now.

\section{Conclusion}

Association of rare cervical vagus nerve schwannoma with bicuspid aortic valve, with aortic stenosis and dilation of ascending aorta, is a rare occurrence. Also, in patients presenting with symptom of hoarseness of voice, it is very crucial to determine the underlying cause by differential diagnosis.

\section{References}

[1] Fennessy, B., Sheahan, P. and McShane, D. (2008) Cardiovascular Hoarseness: An Unusual Presentation to Otolaryngologists. The Journal of Laryngology \& Otology, 122, 327-328. http://dx.doi.org/10.1017/S0022215107008110

[2] Subramaniam, V., Herle, T., Mohammed, N. and Thahir, M. (2011) Ortner's Syndrome: Case Series and Literature Review. Brazilian Journal of Otorhinolaryngology, 77, 559-562. http://dx.doi.org/10.1590/S1808-86942011000500004

[3] Shahul, H.A., Manu, M.K., Mohapatra, A.K. and Magazine, R. (2014) Ortner’s Syndrome. BMJ Case Reports, 2014. http://dx.doi.org/10.1136/bcr-2013-200950

[4] Saha, S., Bastiaenen, R., Hayward, M. and McEwan, J.R. (2007) An Undiagnosed Bicuspid Aortic Valve Can Result in Severe Left Ventricular Failure. BMJ: British Medical Journal, 334, 420. http://dx.doi.org/10.1136/bmj.39065.624815.80

[5] Tzemos, N., Therrien, J., Yip, J., Thanassoulis, G., Tremblay, S., Jamorski, M.T., et al. (2008) Outcomes in Adults with Bicuspid Aortic Valves. JAMA, 300, 1317-1325. http://dx.doi.org/10.1001/jama.300.11.1317

[6] Colreavy, M., Lacy, P., Hughes, J., Bouchier-Hayes, D., Brennan, P., O’Dwyer, A., et al. (2000) Head and Neck Schwannomas-A 10 Year Review. Journal of Laryngology \& Otology, 114, 119-124. http://dx.doi.org/10.1258/0022215001905058

[7] Sreevatsa, M. and Srinivasarao, R.V. (2011) Three Cases of Vagal Nerve Schwannoma and Review of Literature. Indian Journal of Otolaryngology and Head \& Neck Surgery, 63, 310-312. http://dx.doi.org/10.1007/s12070-011-0220-z

[8] Sérémé, M., Ouédraogo, A., Gyébré, Y. and Ouoba, K. (2014) Cervical Vagal Schwannoma: Difficulty of Diagnosis and Particularity of Treatment. The Internet Journal of Otorhinolaryngology, 16.

[9] Gibber, M.J., Zevallos, J.P. and Urken, M.L. (2012) Enucleation of Vagal Nerve Schwannoma Using Intraoperative Nerve Monitoring. The Laryngoscope, 122, 790-792. http://dx.doi.org/10.1002/lary.22485 